\title{
Vertebrate Taxonomy
}

National Cancer Institute

\section{Source}

National Cancer Institute. Vertebrate Taxonomy. NCI Thesaurus. Code C19059.

The systematic classification of vertebrates. 